Article

\title{
How Knowledge Acquisition Diversity Affects Innovation Performance during the Technological Catch-Up in Emerging Economies: A Moderated Inverse U-Shape Relationship
}

\author{
Qiang Li ${ }^{1}\left(\mathbb{D}\right.$, Jing-Jing Guo ${ }^{2,3}$, Wei Liu ${ }^{4, *}$, Xiao-Guang Yue ${ }^{5,6, *}$, Nelson Duarte ${ }^{6} \mathbb{D}$ and \\ Carla Pereira ${ }^{6,7}$ \\ 1 School of Business, Zhejiang University City College, Hangzhou 310015, China; liq@zucc.edu.cn \\ 2 Institutes of Science and Development, Chinese Academy of Sciences, Beijing 100190, China; \\ guojingjing@casipm.ac.cn \\ 3 School of Public Policy and Management, University of Chinese Academy of Sciences, Beijing 100039, China \\ 4 Business School, Qingdao University, Qingdao 266100, China \\ 5 Department of Computer Science and Engineering, School of Sciences, European University Cyprus, \\ Nicosia 1516, Cyprus \\ 6 CIICESI-ESTG, Porto Polytechnic, Felgueiras 4610-156, Portugal; nduarte@estg.ipp.pt (N.D.); \\ csp@estg.ipp.pt (C.P.) \\ 7 INESC TEC, Porto 4200-465, Portugal \\ * Correspondence: wei.liu2@sydney.edu.au (W.L.); x.yue@external.euc.ac.cy (X.-G.Y.)
}

Received: 27 November 2019; Accepted: 22 January 2020; Published: 28 January 2020

\begin{abstract}
Many domestic enterprises in emerging economies are concerned with the question of how to better utilize the portfolio of technology sourcing channels to achieve rapid economic growth by technological innovation. This paper looks at this issue by exploring the impacts of knowledge acquisition diversity (KAD) on innovation performance of domestic enterprises in China and the technological contexts (in terms of technology gap and technology development speed) under which KAD is most likely to contribute. Using panel data of the manufacturing industry in China over the 2001-2009 period, the results show that KAD has an inverse U-shaped relationship with innovation performance in terms of both product-related innovation performance (NPS) and knowledge-related innovation performance (PAT). Specifically, it reveals that the capability to generate technological innovation over time is dependent on how domestic enterprises manage their portfolio of knowledge sourcing channels to learn from foreign enterprises. Moreover, it is shown that the technology gap significantly moderates the inverted U-shaped relationship between KAD and both NPS and PAT. Technology development speed has a moderating effect on the inverted U-shaped relationship between KAD and innovation only in terms of NPS. The results of this study can help us to understand the relationships among technological contexts, KAD and innovation performance of domestic enterprises in emerging countries.
\end{abstract}

Keywords: knowledge acquisition diversity (KAD); innovation performance; technology gap; technology development speed; emerging economies

\section{Introduction}

Ever since joined World Trade Organization (WTO) in 2001, the Chinese government has nurtured an "indigenous innovation" policy designed to promote the sustainable competitiveness of Chinese domestic enterprises. So far, Chinese domestic enterprises even "leapfrog" foreign enterprises in some fields and become major competitors in several industries such as 5G telecom, high-speed rail, 
solar photovoltaic, and home appliances. These industries have gained market leadership through competing not only in excellent manufacturing capabilities, but also in innovation as well. However, not all industries have been successful in making this transition, and the technological innovation process in many industries has become doubtful. For academic scholars and government officials in less developed economies, how to enhance the innovativeness of domestic enterprises and achieve sustainable economic development has been one of hot issues for decades. As an integral part of technological learning for domestic enterprises in emerging economies, acquisition of external knowledge and technologies from both international and domestic channels plays an essential role in facilitating the innovation of domestic enterprises from developing countries [1-5]. Among them, the importance of acquiring external knowledge through different channels has widely been recognized, including purchases or transfer of technology from foreign as well as domestic agencies, spillover from foreign direct investment (FDI) or R\&D activities of other enterprises [6-10].

One of the reasons for domestic enterprises' sourcing knowledge externally is to access, acquire and integrate the heterogeneous or non-redundant knowledge from highly productive foreign enterprises [11,12], especially in an age of increasing "distributedness" of external knowledge and innovation process across various actors [13]. As a consequence, domestic enterprises may access a wide spectrum of technology sourcing channels to enhance accessibility to a broader pool of existing knowledge stock [14], thereby allowing domestic enterprises to create new combinations of technology and knowledge [15]. Although a few studies have clearly pointed to the portfolio aspects of technology sourcing channels [7], most of those studies focus on the relative contribution of these channels $[2,8,16]$ or the interaction of several sourcing channels to technological advance $[6,7,10]$. Much less attention has been paid to the effect of various technology sourcing channels at a portfolio level and investigates the effect of the portfolio of technology sourcing channels (referred to as "knowledge acquisition diversity") on the innovation performance of domestic enterprises in emerging countries [17-19].

The second rationale for sourcing knowledge externally is to capture the abundance of existing knowledge stock. External knowledge acquisition does not occur in a vacuum but critically relies on the particular technological context where technical problem-solving activities take place $[17,20,21]$. Technology regime research at the industry level underlines the role of preexisting knowledge bases for successful catch-up of latecomers (referred to the domestic enterprises in developing countries) and suggests that the technological contexts with more knowledge stock will generate more technology opportunities [20,22]. Regarding the technological contexts of catching-up in emerging economies, technology development speed and the technology gap have long been recognized as fundamental features of technological contexts in prior work on technological regime, technological catching-up and innovation $[20,23,24]$. In this paper, the technology gap refers to the differences in the level of knowledge between foreign-owned enterprises and typically more lagged behind domestic enterprises at the industry level [21]. Technology development speed refers to the speed that a certain technology develops or evolves along the technology trajectory [22]. Nonetheless, as far as we know, no empirical study has been conducted to elucidate whether and how technological contexts influence the relationship between diversity of technology sourcing channels (referred to as "knowledge acquisition diversity") and innovation performance at the industry level. Our study proposes that the characteristics of technological contexts will significantly determine the payoff from the access, integration, and recombination of external knowledge from diverse technology sourcing channels $[11,25]$, and thereby moderating the effect of knowledge acquisition diversity (KAD) on innovation outcomes. As such, our study will explain the reason why some industrial sectors are able to take advantage of knowledge from technology sourcing channels more efficiently than others.

To address the above two research gaps in prior literature, this study will adopt a portfolio-based perspective of external knowledge acquisition at the industry-level. Specifically, using the industry-level dataset of Chinese manufacturing from 2001 to 2009 (from 2001 and forward, China has gone through a transition period featuring "indigenous innovation" and leapfrogged in various technological areas [26]), this paper will investigate how KAD affects innovation performance in terms of product-related 
innovation performance (NPS) and knowledge-related innovation performance (PAT) and also examine the contingency effect of technological contexts. Our paper contributes to the literature on external knowledge acquisition and technology regime literature in the following aspects. First, it improves our understanding of external knowledge acquisition in emerging economies. Specifically, we extend a portfolio concept to external knowledge acquisition at the industry level, and find a curvilinear relationship between KAD and innovation performance both in terms of NPS and PAT. Most importantly, we attempt to introduce a framework integrating external knowledge acquisition and technology regime literature for understanding external knowledge acquisition occurring during technological catching-up process of domestic enterprises. It indicates that technology gap and technology development speed may influence the effect of KAD on innovation performance of domestic enterprises. The remainder of this study proceeds as follows. In the second section, it reviews and develops theoretical framework and hypotheses. In the third section, the methodology section is followed behind with the data collection, measurement of variables and regression results. The results of regression analyses are presented in the fourth section. Finally, in the fifth section, it will discuss the key findings and managerial implications, and then conclude.

\section{Theory and Hypotheses}

Based on the accumulation of knowledge, technological innovation has a crucial role in the growth strategy of both emerging economies and domestic enterprises. Since innovation is a result of novel combinations of multiple technology and knowledge elements, it usually takes a large amount of resources, such as time and money [9,27]. For emerging countries where few domestic enterprises have well-established R\&D operations and resources, tapping into the external world knowledge stock would seem to be a feasible and arguably more efficient way than trying to improve their technology through indigenous R\&D effort [28]. Therefore, accessing, acquiring, and leveraging existing knowledge from foreign counterparts is regarded as a primary means for technological capability building and technical progress of domestic enterprises $[8,29,30]$.

There are various channels of external knowledge acquisition for domestic enterprises in emerging countries such as market-mediated purchases or technology transfer from international as well as domestic markets, knowledge spillovers from foreign investment, other foreign affiliates, and domestic firms [6-10]. Among those channels, some knowledge is transferred intentionally through formal mechanisms from the knowledge owner to the recipient (e.g., technology transfer from foreign and domestic technology market), but a large proportion of knowledge spillovers take place as unintentional knowledge leakage [31]. These sourcing channels can contribute to innovation of domestic enterprises in several ways such as learning through labor mobility whereby employees of foreign firms migrate to domestic enterprises, leakage of intellectual property, and imitation (e.g., reverse engineering) of foreign firms' products and technologies by domestic enterprises, or vertical linkages whereby foreign firms bring local suppliers in their supply value chains [32]. In brief, those types of channels and interaction with foreign firms may contribute to innovation and knowledge creation of domestic enterprises.

Most research in this field focuses on the differential effects of technology sourcing channels on innovation performance $[14,33]$ and the spillover effects from foreign investments and domestic industrial firms $[3,29]$. These studies have considerably advanced our understanding of domestic enterprises' choice of technology sourcing channels. However, the anecdotal evidence also highlights that domestic enterprises develop their technology capability using a combination of technology sourcing channels $[17,18,34]$. Different types of technology sourcing channels are appropriate in different situations, such as the attributes of the technology being pursued and the degree of technical change and uncertainty [24,34,35]. For example, Zhou, Pan, and Urban (2018) found that technology sourcing channels such as equipment acquisition and knowledge transfer from other manufactures take a very different form in China's solar PV sector than the wind energy sector [34]. Van de Vrande, Vanhaverbeke, and Duysters (2009) found that the benefits of using a particular type of external technology sourcing are contingent on environmental turbulence, emerging technologies, and the technological distance between partners [24]. Arora and Gambardella (1990) suggest that firms need 
to pursue different types of technology sourcing linkages to access different types of knowledge [36]. As such, the diversity of technology sourcing channels may allow domestic enterprises to access diverse markets and technological knowledge stocks. However, previous studies have also mentioned that such knowledge transfer requires substantial interaction and investments by domestic enterprises, resulting in escalating costs. For example, it requires absorptive capacity to absorb and integrate knowledge embodied in equipment, people, and organizational routines in a foreign firm $[10,11,31]$. To get the full picture of how domestic enterprises benefit or suffer from a variety set of technology sourcing channels, we need to take a portfolio-based perspective in examining the effect of knowledge acquisition diversity on innovation performance.

\subsection{Knowledge Acquisition Diversity (KAD) and Innovation Performance}

While considering the contexts of emerging economies, technologically lagging domestic enterprises need to search and source across a portfolio of technology sourcing channels for acquiring technology and knowledge developed by foreign companies in order to improve innovation [12,20,37]. In this paper, KAD is defined as the extent to which the domestic enterprises may acquire technology and knowledge through a variety of technology sourcing channels from highly productive foreign enterprises [17]. The literature suggests that the effect of KAD on innovation is a function of accessing, acquiring, and integrating external knowledge $[29,38]$. We argue that KAD may have an inverted U-shaped relationship with innovation performance in terms of NPS and PAT.

First of all, various types of technology sourcing channels can enhance accessibility to knowledge flow from highly productive foreign enterprises, which allows domestic enterprises to tap into a broader pool of existing knowledge stock [20]. Since industrial firms in advanced economies create most of knowledge stock, domestic enterprises in emerging countries can at best access and utilize the external "public" knowledge for production [39]. Nevertheless, external knowledge is known to be distributed over various actors and diverse geographic location $[13,40]$. In such a case, the widely distributed knowledge can only be accessible through a multitude of technology sourcing channels. Besides, the foreign enterprises in advanced economies who have the "state-of-the-art" technologies will usually establish sophisticated procedures to control the transfer of knowledge to domestic enterprises $[10,17]$. Pursuing multiple types of knowledge sourcing linkages simultaneously may give domestic enterprises enormous bargaining power while negotiating the transfer of state-of-the-art technologies from the foreign enterprises [26]. Based on these arguments, we argue that knowledge acquisition diversity may increase the likelihood of accessing a larger knowledge stock in an industry which ultimately will have a beneficial effect on innovation performance.

Moreover, diversified knowledge channels may also allow domestic enterprises to acquire heterogeneous knowledge domains from highly productive foreign enterprises. The literature suggests that each type of technology sourcing channels possesses different knowledge and technology in terms of contents and characteristics [36]. Thus, domestic enterprises need to pursue multiple types of knowledge sourcing channels to acquire heterogeneous knowledge, which affects their innovation activities positively through at least two mechanisms. First, knowledge from different sources will result in cross-validation, which helps the latecomer to lower the risk of choosing the right technology out of alternative technologies or standards [41]. Learning by comparison and trial-and-error will help domestic enterprises identify suitable external sources and understand the value of technology acquired externally [42]. Therefore, accessing knowledge from multiple technology sourcing channels will reduce the risk of locking into a technology that will probably be replaced by a new technological paradigm $[35,43]$. It allows domestic enterprises to stay flexible to identify and seize technological opportunities as they emerge, and as a consequence, it enhances the likeliness that the best potential technology will be selected in the long run. Second, diversified technology sourcing channels will also enhance the possibilities for finding a new recombination of knowledge elements and generate new applications for existing knowledge, thus facilitating innovation through novel combinations of readily accessible pieces of external knowledge [44]. Overall, the above arguments suggest that dispersed knowledge channels should lead to better innovation performance. 
However, there are limits to these positive effects and too much of KAD will lead to a negative effect on innovation performance due to rapid escalation of difficulties and costs in knowledge integration across a variety of technology sourcing channels $[45,46]$. Accessing external technology sourcing channels on their own are insufficient to account for the success of domestic enterprises without further investment in learning [47]. Domestic enterprises must have the capabilities to integrate existing knowledge stock with externally acquired knowledge for innovation $[10,11]$. As KAD increases, the proportion of new knowledge to be integrated into an industry' knowledge base increases and so do the difficulty in integration [38]. In fact, a firm with a limited absorptive capacity, particularly in the case of latecomer firms, suffer greatly from resource constraint problem. Hence, over-search from too many different sources challenges domestic enterprises' absorptive capacity and makes it harder to assimilate the new technologies. Furthermore, too many new knowledge and technologies to be integrated can also lead to the "search recency" problem, which means there is not enough time for domestic enterprises to absorb and exploit external knowledge before launching their product on the market [9]. In sum, we posit a curvilinear relationship between knowledge acquisition diversity and innovation performance.

Hypothesis 1a. Knowledge acquisition diversity $(K A D)$ has an inverted $U$-shaped relationship with innovation performance in terms of product-related innovation performance (NPS).

Hypothesis $\mathbf{1 b}$. Knowledge acquisition diversity $(K A D)$ has an inverted $U$-shaped relationship with innovation performance in terms of knowledge-related innovation performance (PAT).

\subsection{Contingent Role of Technological Contexts}

Technological contexts will affect the availability of external knowledge as well as the way how a firm takes advantage of knowledge, and thus will create a set of opportunities or constrains for external knowledge acquisition [11,20,21,25]. We expect two features of technological contexts to affect the convexity of KAD-innovation performance relationship.

\subsubsection{The Moderating Role of the Technology Gap}

One of important features of technological contexts affecting the impact of KAD on innovation performance is the role of the technology gap between domestic enterprises and foreign-owned enterprises. Technology gap refers to the differences in the level of knowledge between foreign-owned enterprises and typically more lagged behind domestic enterprises at the industry level [21]. On the one hand, many scholars propose that a larger technology gap may mean a larger potential that domestic enterprises can learn from their foreign counterparts in developed countries $[41,48,49]$. It may alleviate foreign counterparts' concerns of losing the control of advanced technology, and as a result the domestic enterprises, could more likely and easily access to state-of-the-art technology and knowledge. While domestic enterprises gradually close the technology gap with their foreign counterparts, they will find it harder and more expensive to acquire the technologies required for the higher-level market [41]. In such circumstances, a diversity of knowledge channels adopted by domestic enterprises becomes more important to enhance bargaining power when dealing with knowledge transfer from foreign-owned enterprises.

On the other hand, the studies have suggested that the larger the technology gap between foreign-owned enterprises and domestic enterprises, the lower the absorptive capacity of the latter [21,23]. Consistent with the absorptive capacity perspective, this underlines the significance of a small technology gap on innovation and R\&D activities [41,48]. A large technology gap may make the domestic enterprises unable to acquire, assimilate, and use the new technology from foreign rivals. For example, Haddad and Harrison (1993) found that a large technology gap restrains FDI spillovers [50]. Therefore, we expect the domestic enterprises in industry with small technology gap benefit more by cross-validation and recombination of knowledge derived from KAD than those in industry with large technology gap. More specifically, when the technology gap between foreign-owned enterprises 
and domestic enterprises in the same industry is large, domestic enterprises generally do not have sufficient absorptive capacity to judge the value of different sources of knowledge and choose the right technological solution [21] and then cross validate or recombination knowledge through various technology sourcing channels will be less feasible for the domestic enterprises to learn from foreign enterprises and build their own technological capability. Conversely, when domestic enterprises narrow the technology gap with foreign enterprises, they will be capable to identify the value of knowledge and choose the feasible source of technology based on their absorptive capacity.

At the same time, with an increasing technology gap acting as a barrier in absorptive capacity, domestic enterprises may incur higher costs in knowledge integration across multiple-sourced knowledge. Scholars have identified a high level of technology gap with a low level of absorptive capacity for domestic enterprises that are too weak to effectively integrate external technological knowledge for innovation activity because of their lack of in-house R\&D and prior knowledge [50]. Therefore, when the technology gap increases, it can be more difficult and costly for domestic enterprises with reliance on external knowledge acquisition to integrate and utilize the knowledge from a various of technology sourcing channels. This suggests that, as technology gap increases, the detrimental effect of KAD is likely to increase. Taken together, we conclude that the technological gap moderates the invert-U effect of knowledge acquisition diversity on industry-level innovation performance.

Hypothesis 2. The technology gap moderates the inverse U-shaped relationship between knowledge acquisition diversity $(K A D)$ and innovation performance in terms of product-related innovation performance and knowledge-related innovation performance.

\subsubsection{The Moderating Role of Technology Development Speed}

We also argue that technology development speed has potentially contingent effects on the relationship between KAD and innovation performance. Technology development speed refers to the speed that a certain technology develops or evolves along the technology trajectory [22,41]. Some scholars have pointed out that a high speed of technology development means that knowledge in the field changes and quickly becomes obsolete [20]. In such circumstances, external knowledge acquisition from various sources can provide domestic enterprises with quick access to embodied technology and easier entry into production [51]. Additionally, maintaining flexibility and avoiding not being locked into an obsolete technological paradigm is more critical for domestic enterprises in the industry with high technology change [52]. When technology in an industry changes rapidly, domestic enterprises may face greater uncertainty and lack information in respect of potential application of new technology to existing market and technology. An industry's technological trajectory can also become unpredictable if fast changes to technology render existing knowledge obsolete at an increasing pace. Previous research has suggested that a flexible innovation approach which keeps innovation option open is particularly effective in "high-velocity" industry [24,53]. Therefore, in the presence of high technology change, the beneficial effect of flexibility deriving from KAD will be more critical for the innovation performance of domestic enterprises. Moreover, to keep pace with rapid changes of technology environment and avoid the "lock-in" effect, domestic enterprises frequently need to make great and deliberate effort to obtain advanced foreign technology through a variety of technology sourcing channels, which bring tremendous opportunities to practice technological learning and improve their R\&D capabilities. Eventually, the beneficial effects of KAD on innovation performance may be enhanced by the condition of a high technology development speed.

Nevertheless, a high technology development speed is also associated with huge challenges in search and integration because of the constrains on technological accumulation and capability building for domestic enterprises [54]. When technology in an industry changes quickly, the disadvantages of integration of multiple-sourced knowledge for domestic enterprises might be very large. As we discussed earlier, the integration of knowledge and technology in a field from a variety of existing sources or channels require a lot of time [55]. When technology development speed in an industry is high, product-related technology or knowledge in emerging countries are more likely to very quickly 
become obsolete [20]. Then, the main challenge for domestic enterprises is to discern clearly how to adapt existing technologies and enter market as fast as possible for its innovation endeavors. Under such circumstance, the integration problem associated with time tend to be stronger. In other words, the negative effects of the "over-search" of external knowledge acquisition tend to be much more critical for industries with high technology development speed than for those with low technology development speed. Based on these arguments, we propose,

Hypothesis 3. Technology development speed moderates the inverse U-shaped relationship between knowledge acquisition diversity (KAD) and innovation performance in terms of product-related innovation performance and knowledge-related innovation performance.

\section{Methods}

\subsection{Sample and Data}

Our study uses a 2001-2009 industry-level panel data set of large and medium size manufacturing enterprises in China. We collected the data from the China Statistical Yearbook on Science and Technology and the Statistical Yearbook of China, both of which are published by National Bureau of Statistics in China. The yearbooks release the industry-level annual data of large and medium size manufacturing enterprises for 29 manufacturing industries (grouped by two-digit Standard Industrial Classification code). Because of incomplete data or harsh government regulation, three industries are excluded from analysis including processing of petroleum, coking, nucleus fuel, artwork manufacture, and tobacco manufacture. At last, 26 manufacturing industries (refer to Tables 1 and 2 for more details) are included in the analysis. Specifically, the data collected from the China Statistical Yearbook on Science and Technology include expenditure on purchase of domestic technology, intramural expenditure on technical development, expenditure on technology import and absorption, industry-level aggregates of firm number, number of employees at year-end, sales revenue, sales revenue of new products, number of patent applications, and original value of microelectronic equipment. Besides, assets of foreign-funded industrial enterprises, assets of all industrial enterprises above designated size, gross value of industrial output, value-added, and value added tax payable of industrial enterprises are collected from the Statistical Yearbook of China.

Table 1. New product sales (unit: 10,000 RMB) per 1000 employees in each industry (2001-2008).

\begin{tabular}{|c|c|c|c|c|c|c|c|c|}
\hline Industries & 2001 & 2002 & 2003 & 2004 & 2005 & 2006 & 2007 & 2008 \\
\hline Food processing & 2.7 & 3.2 & 2.5 & 2.7 & 4.2 & 6.2 & 9.5 & 14.2 \\
\hline Food production & 4.2 & 4.7 & 6.2 & 6.4 & 6.3 & 9.5 & 11.6 & 14.0 \\
\hline Beverage production & 4.3 & 5.9 & 7.0 & 9.2 & 8.6 & 14.5 & 16.3 & 16.9 \\
\hline Textile industry & 3.7 & 4.9 & 5.7 & 6.6 & 6.9 & 7.3 & 8.2 & 8.9 \\
\hline Garments and other fiber products & 5.1 & 5.8 & 3.0 & 5.9 & 5.9 & 4.1 & 5.3 & 4.3 \\
\hline Leather, furs, down and related products & 7.7 & 4.6 & 3.4 & 3.5 & 3.5 & 3.2 & 4.1 & 4.1 \\
\hline Timber, bamboo, cane, palm fiber and straw products & 4.8 & 2.4 & 2.3 & 7.6 & 9.6 & 9.0 & 9.6 & 12.4 \\
\hline Furniture manufacturing & 5.6 & 6.5 & 2.6 & 6.5 & 6.0 & 6.2 & 7.5 & 5.2 \\
\hline Paper making and paper products & 7.3 & 10.1 & 10.3 & 12.8 & 7.2 & 18.1 & 20.7 & 23.1 \\
\hline Printing and record medium reproduction & 4.6 & 3.1 & 3.4 & 4.7 & 6.4 & 7.7 & 7.6 & 8.1 \\
\hline Culture, educational and sports goods & 3.5 & 3.4 & 2.0 & 2.4 & 3.0 & 3.1 & 3.4 & 3.6 \\
\hline Raw chemical materials and chemical products & 6.9 & 9.4 & 10.1 & 16.6 & 17.1 & 19.3 & 27.3 & 29.9 \\
\hline Medical and pharmaceutical products & 12.6 & 12.7 & 16.4 & 19.8 & 20.6 & 22.6 & 27.0 & 30.2 \\
\hline Chemical fiber & 17.0 & 20.7 & 20.7 & 24.2 & 41.6 & 39.3 & 44.8 & 52.9 \\
\hline Rubber products & 7.5 & 10.8 & 12.3 & 18.2 & 25.4 & 23.8 & 28.5 & 26.8 \\
\hline Plastic products & 11.1 & 10.1 & 7.7 & 9.8 & 9.3 & 9.4 & 10.5 & 11.6 \\
\hline Nonmetal mineral products & 2.3 & 2.3 & 3.0 & 4.5 & 5.9 & 7.5 & 8.3 & 9.3 \\
\hline Smelting and pressing of ferrous metals & 7.3 & 11.3 & 13.8 & 25.9 & 29.8 & 34.7 & 45.6 & 59.0 \\
\hline Smelting and pressing of nonferrous & 4.7 & 7.2 & 8.6 & 10.7 & 22.3 & 37.0 & 36.3 & 33.3 \\
\hline Metal products & 5.5 & 6.9 & 6.7 & 7.7 & 9.5 & 9.7 & 13.0 & 16.5 \\
\hline Ordinary machinery & 10.7 & 16.0 & 20.1 & 24.7 & 29.0 & 32.6 & 37.7 & 39.0 \\
\hline Equipment for special purposes & 10.3 & 14.2 & 16.6 & 19.7 & 18.7 & 27.0 & 33.4 & 35.6 \\
\hline Transport equipment & 31.3 & 44.5 & 57.9 & 63.2 & 66.8 & 84.7 & 94.8 & 89.9 \\
\hline Electric equipment and machinery & 36.6 & 43.9 & 36.2 & 36.6 & 39.8 & 38.8 & 47.5 & 46.9 \\
\hline Electronic and telecommunications equipment & 75.3 & 84.6 & 71.6 & 62.4 & 56.2 & 52.6 & 55.3 & 55.2 \\
\hline Instruments, meters, cultural and office machinery & 9.9 & 18.2 & 13.4 & 19.5 & 18.3 & 19.4 & 26.5 & 24.1 \\
\hline Averages & 11.6 & 14.1 & 14.0 & 16.6 & 18.4 & 21.1 & 24.6 & 26.0 \\
\hline
\end{tabular}


Table 2. Number of inventive patent applications per 1000 employees in each industry (2001-2008).

\begin{tabular}{|c|c|c|c|c|c|c|c|c|}
\hline Industries & 2001 & 2002 & 2003 & 2004 & 2005 & 2006 & 2007 & 2008 \\
\hline Food processing & 0.15 & 0.17 & 0.16 & 0.48 & 0.19 & 0.47 & 0.40 & 0.58 \\
\hline Food production & 1.84 & 1.49 & 1.15 & 1.98 & 1.03 & 1.88 & 1.44 & 1.55 \\
\hline Beverage production & 0.95 & 1.08 & 1.47 & 1.88 & 1.90 & 1.47 & 1.38 & 1.57 \\
\hline Textile industry & 0.15 & 0.25 & 0.20 & 0.26 & 0.44 & 0.63 & 1.48 & 1.81 \\
\hline Garments and other fiber products & 0.27 & 0.42 & 0.10 & 0.25 & 0.43 & 0.27 & 0.35 & 0.37 \\
\hline Leather, furs, down and related products & 0.09 & 0.06 & 0.10 & 0.12 & 0.12 & 0.14 & 0.22 & 0.38 \\
\hline Timber, bamboo, cane, palm fiber and straw products & 0.20 & 0.16 & 0.09 & 0.59 & 0.50 & 1.52 & 1.19 & 1.19 \\
\hline Furniture manufacturing & 2.75 & 1.90 & 1.18 & 0.44 & 0.47 & 0.68 & 2.19 & 2.58 \\
\hline Paper making and paper products & 0.12 & 0.12 & 0.22 & 0.19 & 0.24 & 0.27 & 0.43 & 0.79 \\
\hline Printing and record medium reproduction & 0.18 & 0.19 & 0.44 & 0.89 & 0.60 & 0.46 & 0.93 & 0.70 \\
\hline Culture, educational and sports goods & 3.28 & 2.81 & 2.42 & 1.41 & 2.60 & 2.20 & 2.47 & 2.52 \\
\hline Raw chemical materials and chemical products & 0.41 & 0.43 & 0.72 & 0.92 & 1.17 & 1.33 & 1.45 & 1.86 \\
\hline Medical and pharmaceutical products & 1.26 & 1.44 & 1.94 & 2.54 & 3.64 & 3.05 & 3.70 & 4.38 \\
\hline Chemical fiber & 0.16 & 0.14 & 0.46 & 0.49 & 0.50 & 0.97 & 1.37 & 1.43 \\
\hline Rubber products & 0.47 & 0.49 & 0.46 & 0.59 & 0.70 & 0.58 & 0.87 & 1.50 \\
\hline Plastic products & 0.67 & 1.94 & 0.64 & 0.79 & 0.69 & 0.90 & 1.13 & 1.44 \\
\hline Nonmetal mineral products & 0.33 & 0.31 & 0.41 & 0.79 & 0.95 & 1.14 & 1.26 & 1.27 \\
\hline Smelting and pressing of ferrous metals & 0.24 & 0.34 & 0.36 & 0.43 & 0.51 & 0.78 & 1.15 & 1.42 \\
\hline Smelting and pressing of nonferrous & 0.33 & 0.61 & 0.68 & 0.90 & 1.25 & 1.65 & 2.00 & 2.54 \\
\hline Metal products & 0.77 & 0.99 & 1.07 & 1.59 & 2.69 & 1.72 & 1.93 & 3.00 \\
\hline Ordinary machinery & 0.60 & 0.67 & 1.18 & 1.79 & 2.23 & 2.61 & 3.04 & 3.50 \\
\hline Equipment for special purposes & 0.75 & 0.99 & 1.51 & 1.86 & 2.09 & 2.75 & 3.68 & 5.26 \\
\hline Transport equipment & 0.54 & 1.08 & 1.75 & 2.19 & 2.64 & 3.34 & 4.26 & 4.19 \\
\hline Electric equipment and machinery & 2.58 & 4.26 & 4.42 & 4.61 & 4.81 & 3.79 & 4.62 & 5.78 \\
\hline Electronic and telecommunications equipment & 1.96 & 3.20 & 3.28 & 3.13 & 4.07 & 4.97 & 6.07 & 5.80 \\
\hline Instruments, meters, cultural and office machinery & 1.42 & 2.37 & 1.57 & 2.79 & 1.77 & 2.39 & 3.07 & 6.04 \\
\hline Averages & 0.86 & 1.07 & 1.08 & 1.30 & 1.47 & 1.61 & 2.00 & 2.44 \\
\hline
\end{tabular}

The reason of collecting data over the period 2001-2009 is that the technological learning process of China could be grouped into four stages: 1949 1960, 1960 1978, 1979 1991, 1992 2000, and 2001 onward [26]. Since entering the WTO in 2001, the Chinese government began to establish a series of policies to foster domestic enterprises to compete in both domestic and global markets and encourage them to acquire the technology developed by foreign companies [32]. In November of 2008, China prompted a four trillion yuan ( $\$ 585$ billion USD) stimulus plan to offset the decline in market demand abroad caused by financial crisis. Therefore, we are concerned that expenditure of technology souring and internal R\&D activities will be seriously disturbed by this large scale fiscal stimulus plan after 2009. Additionally, National Bureau of Statistics of China began to adopt a new standard of division for large and medium size manufacturing enterprises in 2012. Such policy change lead to the data of 2001-2009 incomparable with the data in 2012 and afterwards. Therefore, the year period in this study covers from 2001-2009, using a one-year time lag for all of the independent variables. Eventually, we constructed a panel data of eight years of industry level data with a final size of sample of 208 $(26 \times 8)$. For the purpose of making variables comparable among different industries, this study measures the indicators with ratio data, representing an average firm in each of the two-digit SIC code manufacturing industries [3]. All monetary variables are deflated with producer price index (PPI) from the Statistical Yearbook of China using 1998 as the base year, and the unit of all monetary variables is 10,000 RMB (yuan).

\subsection{Variable Measurement}

\subsubsection{Dependent Variables}

As two important types of innovation output, patents and new products are commonly used indicators to measure industry-level innovation performance [6,56,57]. Patents are usually regarded as a proxy for valuable knowledge-related output, and new product sales is a suitable indicator for commercialized innovation-related output [8]. Thus, we measured industry-level innovation performance using both product-related knowledge output (in terms of new product sale intensity, NPS) and knowledge-related knowledge output (in terms of patent intensity, PAT). 
New product sale intensity (NPS), measured as new product sales divided by the number of full-employed personals in industry $i$ and year $t$ [2]. According to the Chinese industrial statistical convention, the concept of 'new product' could be either completely new in technology and design, or just largely improved in material, structural or process changes [58]. Patent intensity (PAT) is proxied by per capital inventive patent application, specifically which is the ratio of inventive patent application amount to the number of full-employed personals in industry $i$ and year $t$ [8]. The intensity indicators of both measures would eliminate the impacts of the size and make dependent variables comparable across the different 26 industries. Hence, using these two proxy variables enables us to measure the innovation performance appropriately at the industry level.

Tables 1 and 2 provides descriptive statistics about innovation performance in terms of new product sale intensity (NPS) and patent intensity (PAT) for each of the sample industries during 2001-2008. It shows that, during 2001-2008, these two innovation output indicators all demonstrated a continuously increasing tendency in innovation performance. Besides, the leading innovators are Electronic and telecommunications equipment, electric equipment and machinery, transport equipment, equipment for special purposes, and medical and pharmaceutical products.

\subsubsection{Independent Variable}

$\mathrm{KAD}$ is defined as the extent to which domestic enterprises become divergently in acquiring technology or knowledge from a variety of technology sourcing channels such as knowledge spillover from inter-industry R\&D, intra-industry FDI and inter-industry FDI [17]. KAD is constructed in the line of the measurement of diversity using Herfindahl index as follows:

$$
\mathrm{KAD}=\left(1-\sum \mathrm{TSC}_{\mathrm{j}}^{2}\right),
$$

where $\mathrm{TSC}_{\mathrm{j}}$ is the share of the $\mathrm{j}_{\mathrm{th}}$ technology sourcing channels intensity $\left(\mathrm{TSCI}_{\mathrm{j}}\right.$ ) in the technology sourcing portfolio (the sum of five types of technology sourcing channel intensity).

First, we calculated the intensity of five different technology sourcing channels $\left(\mathrm{TSCI}_{\mathrm{j}}\right.$ ). The measurement of these technology sourcing channel intensities $\left(\mathrm{TSCI}_{\mathrm{j}}\right)$ are listed below. First, knowledge spillover from inter-industry $R \& D\left(T_{S C I}\right)$ is measured by the weighted aggregate of intra-industry R\&D expenditure intensity except for the focal industry [3]. Second, knowledge spillover from intra-industry FDI $\left(\mathrm{TSCI}_{2}\right)$ refers to the ratio of foreign-funded enterprises' assets to the total assets of all enterprises in the industry [59]. Third, knowledge spillover from inter-industry FDI $\left(\mathrm{TSCl}_{3}\right)$ is proxied by the weighted aggregate of intra-industry FDI spillover intensity excluding the focal industry [60]; Fourth, domestic technology transfer $\left(\mathrm{TSCI}_{4}\right)$ is the proportion of domestic technology purchase to the total expenditure of science and technology activities in the industry; finally, foreign technology transfer $\left(\mathrm{TSCI}_{5}\right.$ ) refers to the percentage of foreign technology purchase to the total expenditure of science and technology activities in the industry [17]. Secondly, the intensity of five technology sourcing channels $\left(\mathrm{TSCI}_{\mathrm{j}}\right.$ ) are transformed into a same scale range between 1-5 for eliminating the impact of relative scaling of original variables. Finally, KAD is measured using the Herfindahl index mentioned above. For the KAD, the index takes on a range from 0 to 1 . An index of 1 means that all of five technology sourcing channels are equally used by domestic enterprises, while a value of 0 suggests vise verse.

\subsubsection{Moderators}

Previous studies found that the productivity gap between domestic enterprises and foreign-invested enterprises represents the potential for technology transfer and productivity spillovers from the later to the former [21,61]. According to the Statistical Yearbook of China, foreign-invested firms include Sino-foreign joint ventures, enterprises with Sino-foreign cooperation, and wholly foreign-owned enterprises. In our study, technology gap is measured as the difference between the labor productivity (value-added of industry divided by year-end employee number) of domestic firms 
and that of foreign-invested firms located in China. The reason of using the difference between the labor productivity of domestic firms and that of foreign-invested firms as measurement of technology gap is as follow: during initial technological catch-up, the foreign-invested firms have an absolute advantage both in technological and managerial expertise. Although several leading Chinese enterprises, such as Huawei, may learns from the global leading foreign firms, most Chinese domestic firms still target the MNCs or JVs operated and located in China as the benchmark to learn and imitate for a long period of time. Even now, the Chinese firms' technological catch-up in the majority of industries is limited at the domestic market instead of on the global scale. At the same time, in the process of catching-up and capability building from imitation to innovation, the MNCs or JVs in China are usually the main sources from which the domestic firms are learning technology or knowledge. For the domestic Chinese firms, the major objective of technology acquisition and capability building is how to narrow the technology gap with the foreign-invested firms in Chinese market. Therefore, technology gap is calculated as the discrepancy of the labor productivity measured by the ratio of value-added of industry to the number of employees between domestic enterprises and foreign-invested enterprises operated in China [17] as follows:

$$
\text { Technology y gap }_{\mathrm{i}}=\frac{\text { Labour productivity }_{\mathrm{fi}}-\text { Labour productivity }_{\mathrm{di}}}{\text { Labour }_{\text {productivity }}} \text {, }
$$

where the subscripts $i$ denotes the $i_{\text {th }}$ manufacturing industry, and $d$ and $f$ represent domestic enterprises and foreign-invested enterprises, respectively.

Technology development speed is proxied as the annual average growth rate for each industry-year as the percentage change in the amount of inventive patent applications from the previous year [23]. Patent application is usually regarded as a suitable indicator of technology or knowledge development output for both completely new products and existing but improved products in an industry [33].

\subsubsection{Control Variables}

To control for the impact of other extraneous variables, we include industry competition, firm size, R\&D intensity, technological complexity, state ownership (SOEs), and export ratio as control variables [62]. Industry competition is measured as the logarithm of the total number of enterprises in an industry [63]. We measure firm size as the logarithm of the average value of employee number in an industry [57]. We use the share of R\&D expenditure in sale revenues as an indicator of R\&D intensity [6]. We divided the original value of microelectronics-controlled equipment by sales revenue to measure the technology complexity of an industry [17]. We also control for export ratio and state-ownership, where export ratio is measured by the percentage of export amount to gross industrial output in an industry, and state-ownership measures the share of state-owned enterprises (SOEs) in an industry's total equity [8]. Finally, industry dummies and year dummies are also included in the models to control the industries and year fixed effects.

\subsection{Modeling Procedure}

To address potential unobserved effects, we test our hypotheses using industry-level panel data regression method. First, we lag the independent variables by one year to facilitate the causal inferences. Second, since the variables may vary over time and unobserved heterogeneity among the industries may exist, we choose the appropriate models such as random-effects or fixed-effects model according to the Hausman specification test and the Breusch and Pagan Lagrangian multiplier (BP-LM) test. In our analysis, the fixed-effects model is finally selected based on the results of two test, although the results of fixed- or random-effects model do not exhibit significant variation across the models 1-4. Then we use XTSCC command in STATA 14 to deal with panel heteroscedasticity and potential contemporaneous error correlation. In addition, we also try to reduce the potential problem of multicollinearity by data centering all the variables except for dependent variables before generating the interaction terms. 


\section{Results}

The final results of our estimation are reported in Tables 3 and 4 . Table 3 shows descriptive statistics results and correlations coefficients for all variables included in the following regression analyses. We tested three hypotheses with fixed-effect model for both NPS and PAT as the measurements for dependent variable in Table 4. In models 1 and 3, we both find positive coefficient of the linear term and negative coefficient of the quadratic term of KAD. Such results are consistent with the hypothesized curvilinear effect of KAD on innovation performance. Specifically, the coefficients of both KAD $(\alpha=1.3907, p<0.01)$ and KAD squared $(\alpha=-2.8459, p<0.01)$ are significant in model 1 . The coefficients for both KAD $(\alpha=0.0798, p<0.01)$ and KAD squared $(\alpha=-0.1566, p<0.05)$ are significant as well in model 3. In Figure 1, we can see that the strength of the relationship is consistent across NPS and PAT, adding support to Hypothesis 1a,b.

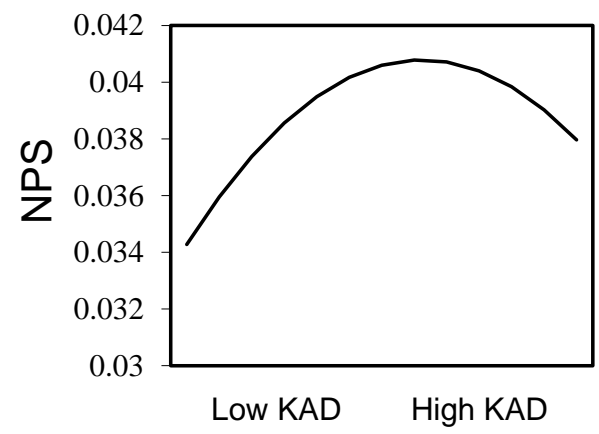

(a)

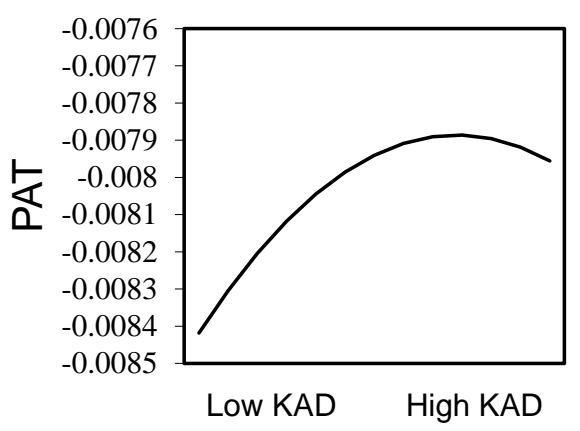

(b)

Figure 1. The inverse U-shape relationship between KAD and innovation performance.

Hypothesis 2 states that technology gap positively moderates the inverse U-shaped relationship between KAD and innovation performance. Models 2 shows that the interaction term between KAD and the technology gap shows a positive and significant impact on product-related innovation performance $(\alpha=0.5115, p<0.05)$, while the interaction between the square term of KAD and technology gap presents a negative and significant effect on product-related innovation performance $(\alpha=-6.8503$, $p<0.05)$. Results in Model 4 reveal that technology gap positively moderates the nonlinear relationship for the knowledge-related innovation performance (KAD $\times$ technology gap: $\alpha=0.0344, p<0.01$; KAD squared $\times$ technology gap: $\alpha=-0.5787, p<0.05)$. In order to gain detailed insights of the moderating effects, we plot the relationships between KAD and two kind of innovation performance measures in Figure $2 \mathrm{a}, \mathrm{b}$ to show how technology gap moderate these relationships. In sum, based on our theory and hypotheses, we find solid support to Hypothesis 2 for both product-related and knowledge-related innovation performance measures. 
Table 3. Descriptive statistics analysis and correlation coefficients (number of samples $=208$ ).

\begin{tabular}{|c|c|c|c|c|c|c|c|c|c|c|c|c|c|}
\hline Variables & Mean & S.D. & 1 & 2 & 3 & 4 & 5 & 6 & 7 & 8 & 9 & 10 & 11 \\
\hline 1. Patent intensity (PAT) & 0.001 & 0.001 & & & & & & & & & & & \\
\hline 2. New product sale intensity (NPS) & 0.018 & 0.018 & 0.600 & & & & & & & & & & \\
\hline 3. Knowledge acquisition diversity (KAD) & 0.236 & 0.026 & -0.087 & 0.075 & & & & & & & & & \\
\hline 4. Knowledge acquisition diversity ${ }^{2}\left(\mathrm{KAD}^{2}\right)$ & 0.584 & 0.040 & 0.143 & -0.119 & -0.649 & & & & & & & & \\
\hline 5. Industry competition ${ }^{1}$ & 6.524 & 0.785 & 0.299 & 0.357 & 0.357 & -0.158 & & & & & & & \\
\hline 6. Firm size ${ }^{1}$ & 6.947 & 0.385 & 0.024 & 0.284 & -0.064 & 0.100 & 0.037 & & & & & & \\
\hline 7. $\mathrm{R} \& \mathrm{D}$ intensity & 0.014 & 0.009 & 0.534 & 0.578 & 0.275 & -0.234 & 0.344 & 0.100 & & & & & \\
\hline 8. Technological complexity & 0.049 & 0.045 & -0.162 & 0.034 & 0.026 & -0.191 & -0.102 & -0.112 & 0.3460 & & & & \\
\hline 9. State ownership & 0.235 & 0.250 & -0.202 & -0.039 & 0.255 & -0.188 & 0.2040 & 0.053 & -0.051 & 0.081 & & & \\
\hline 10. Export ratio & 0.229 & 0.223 & 0.064 & -0.137 & -0.589 & 0.434 & -0.239 & 0.059 & -0.196 & -0.214 & -0.443 & & \\
\hline 11. Technology gap & 0.228 & 0.226 & -0.176 & 0.161 & 0.443 & -0.305 & 0.227 & 0.024 & 0.2090 & 0.2270 & 0.4900 & -0.682 & \\
\hline 12. Technology development speed & 0.433 & 1.182 & 0.025 & 0.027 & -0.035 & -0.023 & -0.076 & 0.063 & 0.113 & 0.066 & -0.151 & 0.176 & -0.159 \\
\hline
\end{tabular}

${ }^{1}$ Natural logarithm is employed; correlations greater than $|0.14|$ are significant at 0.05 . 
Table 4. Regression models for knowledge acquisition diversity (KAD) and innovation performance.

\begin{tabular}{|c|c|c|c|c|}
\hline \multirow[t]{2}{*}{ Variables } & \multicolumn{2}{|c|}{ NPS (Fixed Effects ${ }^{1}$ ) } & \multicolumn{2}{|c|}{ PAT (Fixed Effects ${ }^{1}$ ) } \\
\hline & Model 1 & Model 2 & Model 3 & Model 4 \\
\hline Knowledge acquisition diversity (KAD) & $\begin{array}{l}1.3907^{* *} \\
(0.3083)\end{array}$ & $\begin{array}{c}0.0434 \\
(0.0322)\end{array}$ & $\begin{array}{l}0.0798^{* *} \\
(0.0218)\end{array}$ & $\begin{array}{l}0.0065^{*} \\
(0.0026)\end{array}$ \\
\hline Knowledge acquisition diversity ${ }^{2}\left(\mathrm{KAD}^{2}\right)$ & $\begin{array}{l}-2.8459 * * \\
(0.6659)\end{array}$ & $\begin{array}{l}-2.5795^{* *} \\
(0.4484)\end{array}$ & $\begin{array}{l}-0.1566^{*} \\
(0.0481)\end{array}$ & $\begin{array}{l}-0.1220 * \\
(0.0479)\end{array}$ \\
\hline KAD $\times$ Technology gap & & $\begin{array}{l}0.5115^{*} \\
(0.1607)\end{array}$ & & $\begin{array}{l}0.0344^{* *} \\
(0.0075)\end{array}$ \\
\hline $\mathrm{KAD}^{2} \times$ Technology gap & & $\begin{array}{l}-6.8503 * \\
(2.0689)\end{array}$ & & $\begin{array}{l}-0.5787^{*} \\
(0.1682)\end{array}$ \\
\hline KAD $\times$ Technology development speed & & $\begin{array}{l}0.0228^{+} \\
(0.0119)\end{array}$ & & $\begin{array}{c}0.0010 \\
(0.0016)\end{array}$ \\
\hline $\mathrm{KAD}^{2} \times$ Technology development speed & & $\begin{array}{l}-0.4070^{* *} \\
(0.1133)\end{array}$ & & $\begin{array}{l}-0.0214 \\
(0.0354)\end{array}$ \\
\hline Moderators & & & & \\
\hline Technology gap & & $\begin{array}{l}-0.0010 \\
(0.0114)\end{array}$ & & $\begin{array}{l}-0.0016 \\
(0.0010)\end{array}$ \\
\hline Technology development speed & & $\begin{array}{c}0.0001 \\
(0.0003)\end{array}$ & & $\begin{array}{c}0.00003 \\
(0.00003)\end{array}$ \\
\hline Control variables & & & & \\
\hline Industry competition & $\begin{array}{l}0.0065^{* *} \\
(0.0014)\end{array}$ & $\begin{array}{l}0.0042^{+} \\
(0.0025)\end{array}$ & $\begin{array}{l}0.0008^{* *} \\
(0.0002)\end{array}$ & $\begin{array}{l}0.0005^{* *} \\
(0.0001)\end{array}$ \\
\hline Firm size & $\begin{array}{l}-0.0096^{*} \\
(0.0043)\end{array}$ & $\begin{array}{l}-0.0102 \\
(0.0062)\end{array}$ & $\begin{array}{l}0.0006^{* *} \\
(0.0001)\end{array}$ & $\begin{array}{c}0.0004 \\
(0.0003)\end{array}$ \\
\hline R\&D intensity & $\begin{array}{l}0.8552 * * \\
(0.1663)\end{array}$ & $\begin{array}{l}0.7055^{* * *} \\
(0.1019)\end{array}$ & $\begin{array}{l}0.0808^{* *} \\
(0.0139)\end{array}$ & $\begin{array}{c}0.0599 * * * \\
(0.0060)\end{array}$ \\
\hline Technological complexity & $\begin{array}{c}-0.1391 \text { ** } \\
(0.0336)\end{array}$ & $\begin{array}{c}-0.1200 \text { ** } \\
(0.0276)\end{array}$ & $\begin{array}{c}-0.0077^{* *} \\
(0.0017)\end{array}$ & $\begin{array}{c}-0.0054^{* * *} \\
(0.0007)\end{array}$ \\
\hline State ownership & $\begin{array}{c}-0.0052 * * \\
(0.0014)\end{array}$ & $\begin{array}{c}-0.0029^{+} \\
(0.0013)\end{array}$ & $\begin{array}{l}-0.0002 \\
(0.0002)\end{array}$ & $\begin{array}{c}0.0001 \\
(0.0002)\end{array}$ \\
\hline Export ratio & $\begin{array}{c}0.0005 \\
(0.0012)\end{array}$ & $\begin{array}{c}0.0018 \\
(0.0011)\end{array}$ & $\begin{array}{c}-0.0030 \text { ** } \\
(0.0006)\end{array}$ & $\begin{array}{c}-0.0029 * * \\
(0.0005)\end{array}$ \\
\hline Industry dummies & included & included & included & included \\
\hline Constant & $\begin{array}{c}-0.1291 * * * \\
(0.0372)\end{array}$ & $\begin{array}{c}0.0209 \\
(0.0010)\end{array}$ & $\begin{array}{c}-0.0181^{* * *} \\
(0.0028)\end{array}$ & $\begin{array}{c}0.0016^{* * *} \\
(0.0000)\end{array}$ \\
\hline Number of obs. & 208 & 208 & 208 & 208 \\
\hline $\mathrm{F}$ & $90.6^{* * *}$ & $109.09^{* * *}$ & $4368.92 * * *$ & $5444.04^{* * *}$ \\
\hline $\mathrm{R}^{2}$ & 0.4332 & 0.4901 & 0.5155 & 0.5866 \\
\hline
\end{tabular}

\footnotetext{
${ }^{1}$ Fixed-effects model is run by cross-sectional time-series FGLS regression methods. ${ }^{+} p<0.1 ;{ }^{*} p<0.05 ;{ }^{* *} p<0.01$; *** $p<0.001$. The figures reported within the parentheses are standard errors.
}

Our test of Hypothesis 3 investigates the moderating effect of technology development speed on the inverted U-shaped relationship between KAD and innovation performance. We find a significant interaction effect between the square term of KAD and technology development speed on product-related innovation performance $(\alpha=-0.4070, p<0.01)$. However, we find no interaction effect on knowledge-related innovation performance (KAD $\times$ technology development speed: $\alpha=0.0010$, $p>0.1$; KAD squared $\times$ technology development speed: $\alpha=-0.0214, p>0.1$ ). In Figure 3, it depicts the moderation of technology development speed on the effects of squared KAD on product-related innovation performance. This is consistent with Hypothesis 3. Thus, Hypothesis 3 is at least partially supported. 


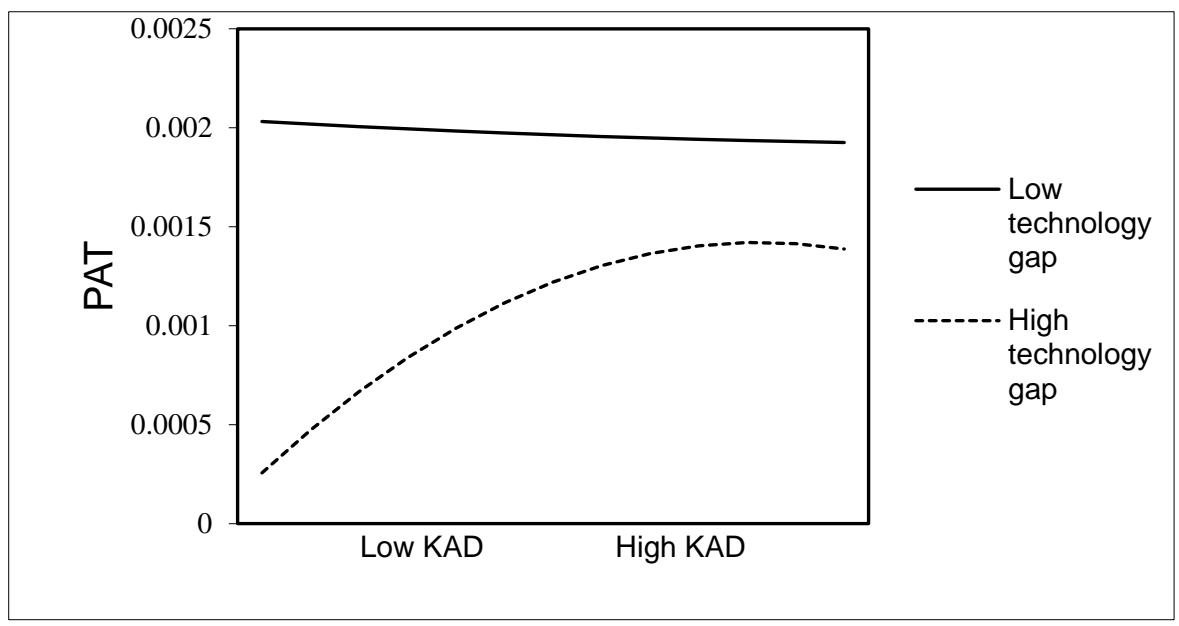

(a)

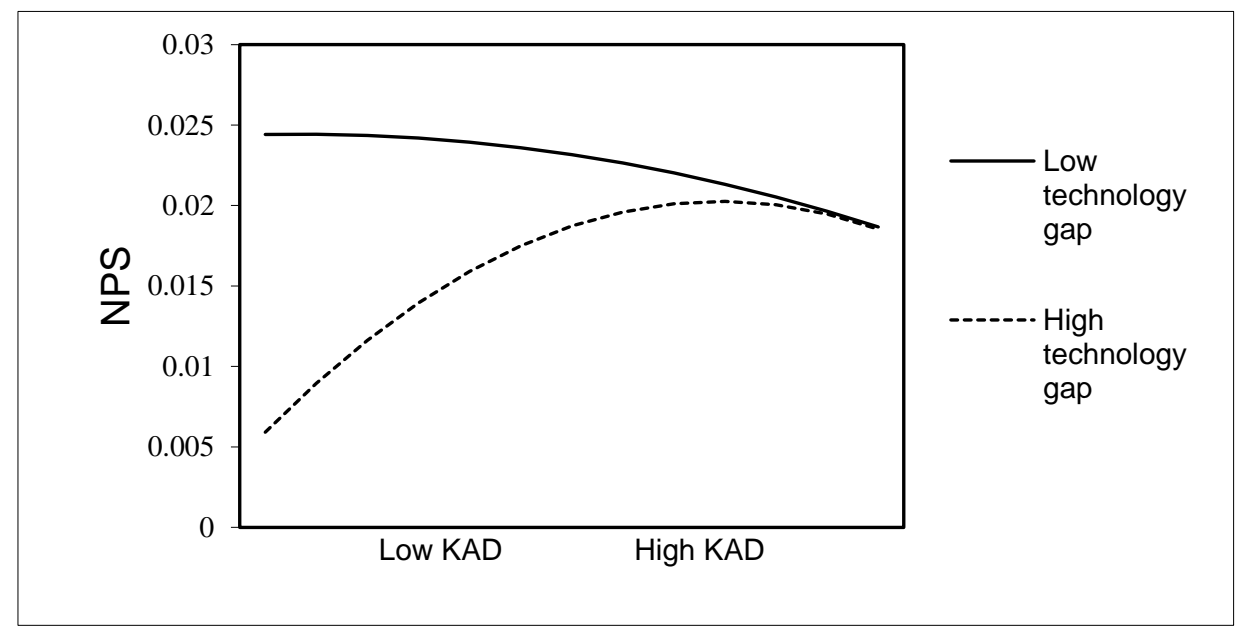

(b)

Figure 2. The moderating role of technology gap on (a) the KAD-PAT relationship and (b) the KAD-NPS relationship.

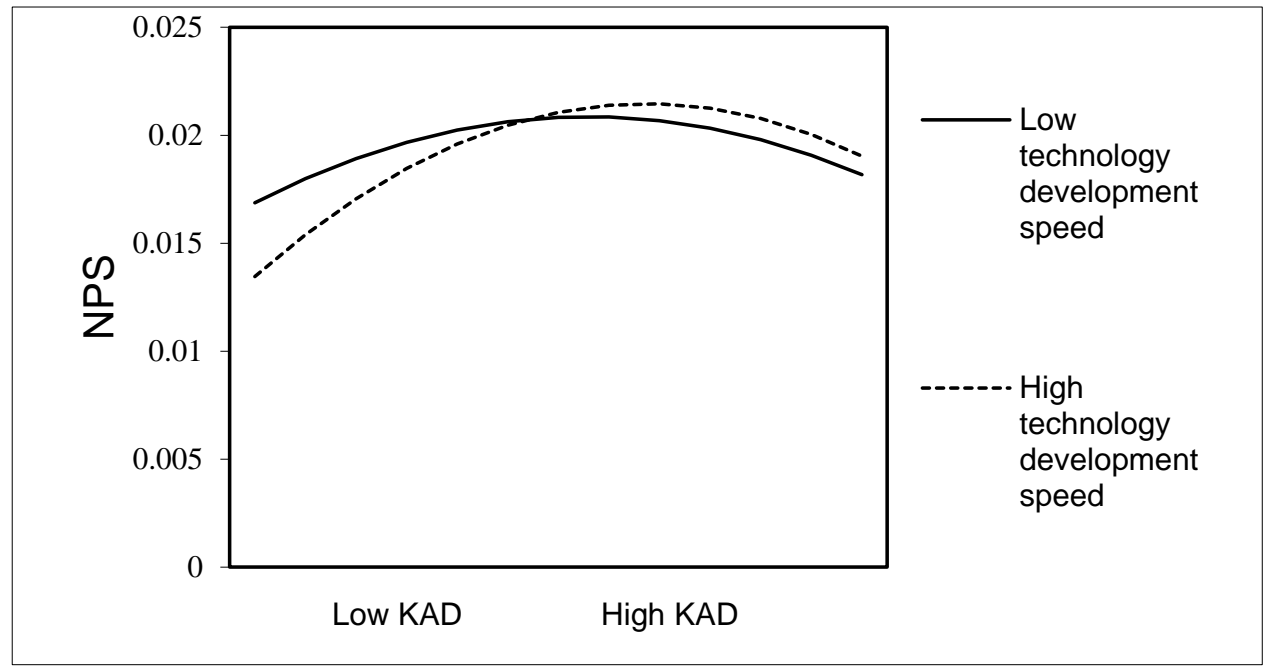

Figure 3. The moderating role of technology development speed on the KAD-NPS relationship. 


\section{Discussion and Conclusions}

The relationship between external knowledge acquisition and innovation performance of domestic enterprises in emerging countries have been attracting a lot of attentions from researchers in the last decades $[4,7,60]$. It requires domestic enterprises not only to gain access to the readily available technology from foreign enterprises but also govern the portfolio of technology searching channels under technological contexts of the industry. Using panel data of the manufacturing industry in China over the 2001-2009 period, we developed a conceptual model that links the portfolio of technology acquisition to innovation performance of domestic enterprises during the catching up process and find a strong evidence for supporting the hypothesized inverse U-shape relationship between KAD and innovation performance both in terms of NPS and PAT, which imply that knowledge acquisition from a diverse sourcing channels has both beneficial and detrimental effects on inventive patent application and new product sales at the industry level. Specifically, the benefits from the increasing accessibility, cross-validation and recombination of heterogeneous external knowledge will outweigh the cost of integration when KAD increases within the range of low to medium, but the detrimental effects due to the escalating integration cost will become to exceed the beneficial effects while KAD raises up beyond a certain level. Hence, this finding is particularly important considering that innovation performance of domestic enterprises rests on the ability of balancing their portfolio of technology sourcing channels: being either too specialized or too diversified in technology sourcing channels is harmful for an industry's inventive patent application and new product sales.

Moreover, our study proposes a contingency model that technological contexts may impact the relationship between KAD and innovation performance. It is shown that that the technology gap significantly moderates the inverted U-shaped KAD—innovation performance relationship in terms of NPS and PAT. It is found that when KAD is within a low-to-medium range, technology gap will attenuate the positive performance effect of KAD. Whereas KAD further raises to a high range, technology gap will exacerbate the negative KAD—innovation performance relationship, whereas it only finds a moderating effect of technology development speed on the inverse U-shaped relationship between KAD and NPS.

These results make several contributions to understanding of the relationship between external knowledge acquisition and innovation performance at the industry level. First, we have endeavored to contribute to existing literature by extending the portfolio concept to external knowledge acquisition at the industry level, and we emphasize the great importance to look at the technology-sourcing portfolio as a whole instead of examining technology sourcing channels as individual things. Domestic enterprises can employ multiple technology sourcing channels to access external knowledge. Most of prior studies at the industry level have emphasized on the benefits and importance of each type of individual sourcing channels for acquiring external knowledge from foreign firms. For example, Wang, Roijakkers, and Vanhaverbeke (2012) explored the role of technology in licensing agreements, long-term alliances with foreign partners, collaboration with local R\&D institutes or universities, and collaboration with the local industrial community on innovative performance [9]. Li and $\mathrm{Wu}$ (2010) estimate the effect of in-house $R \& D$, domestic technology purchase, and foreign technology importing on the innovation output [7]. While the importance of engaging with a variety of knowledge actors, such as competitors, suppliers, clients, and universities, is recognized in the research $[27,64-66]$, it is only recently that scholars have begun to examine the composition of technology sourcing channels at the industry level [17]. Therefore, our study underscores the significance of this new line of inquiry and contributes to the understanding of how the diversity of technology sourcing channels impacts the innovation performance at the industry level.

Second, our study also provides detailed arguments and strong empirical support for a curvilinear relationship between the diversity of technology sourcing channels and innovation performance at the industry level. Hence, this finding will complement the existing body of innovation search studies and allow a strong test of the "over-search" phenomenon by investigating whether it exists across different levels of analysis such as "technology sourcing channels vs. knowledge actors" and "firm-level vs. 
industry-level". Although previous scholars insisted that domestic enterprises are constrained by the limited knowledge diffusion channels [39], this paper also suggests that rapid escalation of difficulties and costs in knowledge integration will also outweigh the benefit of diversified knowledge sources if domestic enterprises over search from diverse technology sourcing channels. In conclusion, our research contributes to the research stream of external knowledge acquisition on the importance of balancing the portfolio of technology sourcing channels at the industry level instead of knowledge actors at the firm level $[19,27]$ and examining its effect on innovation performance at the industry level.

Third, the findings of significant moderating effect of technology gap and technology development speed suggest that for a given industry, technology contexts have a considerable role in determining the extent to which domestic enterprises can suffer or benefit from a variety of technology sourcing channels. On the one hand, although prior studies suggest a larger potential for technology transfer and knowledge spillover brought by large technology gap [21,48,49], our results are consistent with the absorptive capacity perspective $[22,48,50]$ that high technology gap tend to weaken (exacerbate) the positive (negative) effects of KAD on innovation performance when KAD is within the low to medium range (high range). On the other hand, our results are in line with the notion of a "window of opportunity" opened by fast technological change [48], but only when KAD keeps at a low-to-medium level. However, when it moves forward to a high level, technology development speed will exacerbate the negative effect of KAD on innovation performance. In sum, our paper shows that taking, the level of KAD into consideration is the key to reconciling the conflicting results about the effects of technology gap and technology development speed upon innovation performance. Therefore, our study has a more complete explanation of the relationship between KAD and innovation performance.

Finally, our findings provide novel insights for technology regime research, where scholars have found that technology regimes play a crucial role in the catch-up of domestic enterprises [22]. Most of the prior literature has mainly examined the conditions in terms of technological regime which enable domestic enterprises' catch-up to occur [12,20,22,41], or identified technology regime as the key contingency factor influencing the relationship between internal $R \& D$ and technological catch-up performance [23]. We add new insights to this line of research by integrating the research in both technology regime and external knowledge acquisition, indicating that technology regime (e.g., technology gap and technology development speed) can significantly influence the effect of external knowledge acquisition on innovation performance. This is another important aspect of technology regime that is little discussed in the literature of technological catch-up of domestic enterprises in emerging countries. As such, how to exploit a "catch-up opportunity" in technology regime across different industries by external knowledge acquisition, is also an important issue that the government in emerging economies should take into consideration in formulating knowledge transfer-related innovation and industrial policies.

Anyway, our study also has several limitations. First, this study has investigated the effect of $\mathrm{KAD}$ on innovation performance based on the industry-level panel data in China, so the results of our paper may not be generalized to other emerging or developing countries. In the last few decades, the majority of Chinese enterprises tended to be more imitative than originally innovative due to the limited internal R\&D capability and short-term-oriented strategy. Future research could improve our understanding by validating the role of KAD with empirical evidence from other emerging economies. Second, although this study has explained the reason why the time period 2001-2009 was chosen, the findings may not be applicable to the later period of technological catch-up in emerging countries. Future studies using a more recent and valid period of data are encouraged to validate and check the robustness of our findings. Third, we do not account for other contextual factors of technological regime (e.g., appropriability and cumulativeness) that would provide a fuller test of our theories. Finally, the moderating effect of technology development speed is not supported when industry-level innovation performance is measured by patent intensity. Future studies are encouraged to develop more nuanced arguments and check the robustness of our findings by using other measures of technology development speed. 
Author Contributions: Conceptualization, Q.L. and J.-J.G.; methodology, Q.L.; resources, Q.L. and W.L.; writing-original draft preparation, Q.L.; writing—review and editing, J.-J.G., W.L., and X.-G.Y.; supervision, X.-G.Y., N.D., and C.P.; funding acquisition, Q.L. All authors have read and agreed to the published version of the manuscript.

Funding: This research was funded by the Natural Science Foundation of Zhejiang Province, China (grant number LY17G020011), the Humanities and Social Sciences Project of Ministry of Education, China (grant number 16YJC630054), the National Natural Science Foundation of China (grant number 71603235, 71672185), and the Youth Innovation Promotion Association, Chinese Academy of Sciences (grant number 2017201).

Acknowledgments: We deeply thank anonymous reviewers for their insightful suggestions and constructive comments. We are grateful to the editors for their patient work for our manuscript.

Conflicts of Interest: The authors declare no conflict of interest.

\section{References}

1. Mathews, J.A. Competitive advantages of the latecomer firm: A resource-based account of industrial catch-up strategies. Asia Pac. J. Manag. 2002, 19, 467-488. [CrossRef]

2. Liu, X.; Buck, T. Innovation performance and channels for international technology spillovers: Evidence from Chinese high-tech industries. Res. Policy 2007, 36, 355-366. [CrossRef]

3. Guo, B. Technology acquisition channels and industry performance: An industry-level analysis of Chinese large-and medium-size manufacturing enterprises. Res. Policy 2008, 37, 194-209.

4. Qin, X.; Du, D. Do external or internal technology spillovers have a stronger influence on innovation efficiency in China? Sustainability 2017, 9, 1574.

5. Liu, J.; Lu, K.; Cheng, S. International R\&D spillovers and innovation efficiency. Sustainability 2018, 10, 3974.

6. Hu, A.G.; Jefferson, G.H.; Qian, J. R\&D and technology transfer: Firm-level evidence from Chinese industry. Rev. Econ. Stat. 2005, 87, 780-786.

7. Li, X.; Wu, G. In-house R\&D, technology purchase and innovation: Empirical evidences from Chinese hi-tech industries, 1995-2004. Int. J. Technol. Manag. 2010, 51, 217-238.

8. Sun, Y.; Du, D. Determinants of industrial innovation in China: Evidence from its recent economic census. Technovation 2010, 30, 540-550. [CrossRef]

9. Wang, Y.; Roijakkers, N.; Vanhaverbeke, W. Learning-by-licensing: How Chinese firms benefit from licensing-in technologies. IEEE Trans. Eng. Manag. 2012, 60, 46-58. [CrossRef]

10. Wang, Y.; Li-Ying, J. Licensing foreign technology and the moderating role of local R\&D collaboration: Extending the relational view. J. Prod. Innovat. Manag. 2014, 32, 997-1013.

11. Cohen, W.M.; Levinthal, D.A. Absorptive capacity: A new perspective on learning and innovation. Admin. Sci. Quart. 1990, 35, 128-152. [CrossRef]

12. $\mathrm{Mu}, \mathrm{Q}$.; Lee, K. Knowledge diffusion, market segmentation and technological catch-up: The case of the telecommunication industry in China. Res. Policy 2005, 34, 759-783. [CrossRef]

13. Tether, B.S. Who co-operates for innovation, and why: An empirical analysis. Res. Policy 2002, 31, 947-967. [CrossRef]

14. Chen, L.C. Learning through informal local and global linkages: The case of Taiwan's machine tool industry. Res. Policy 2009, 38, 527-535. [CrossRef]

15. Cantwell, J.; Janne, O. Technological globalisation and innovative centres: The role of corporate technological leadership and locational hierarchy. Res. Policy 1999, 28, 119-144. [CrossRef]

16. Wang, Y.; Roijakkers, N.; Vanhaverbeke, W.; Chen, J. How Chinese firms employ open innovation to strengthen their innovative performance. Int. J. Technol. Manag. 2011, 59, 235-254. [CrossRef]

17. Guo, B.; Li, Q.; Chen, X. Diversity of technology acquisition in technological catch-up: an industry-level analysis of Chinese manufacturing. Technol. Anal. Strateg. 2016, 28, 755-767. [CrossRef]

18. Lungeanu, R.; Stern, I.; Zajac, E. When do firms change technology-sourcing vehicles? The role of poor innovative performance and financial slack. Strateg. Manag. J. 2016, 37, 855-869. [CrossRef]

19. Zhang, S.; Yuan, C.; Wang, Y. The Impact of Industry-University-Research Alliance Portfolio Diversity on Firm Innovation: Evidence from Chinese Manufacturing Firms. Sustainability 2019, 11, 2321. [CrossRef]

20. Park, K.; Lee, L. Linking the technological regime to the technological catch-up: Analyzing Korea and Taiwan using the U.S. patent data. Ind. Corp. Change 2006, 15, 715-753. [CrossRef] 
21. Castellani, D.; Zanfei, A. Technology gaps, absorptive capacity and the impact of inward investments on productivity of European firms. Econ. Innov. New Technol. 2003, 12, 555-576. [CrossRef]

22. Lee, K.; Lim, C. Technological regimes, catching-up and leapfrogging: Findings from the Korean industries. Res. Policy 2001, 30, 459-483. [CrossRef]

23. Guo, B.; Gao, J.; Chen, X. Technology strategy, technological context and technological catch-up in emerging economies: industry-level findings from Chinese manufacturing. Technol. Anal. Strateg. 2013, 25, 219-234. [CrossRef]

24. Van de Vrande, V.; Vanhaverbeke, W.; Duysters, G. External technology sourcing: The effect of uncertainty on governance mode choice. J. Bus. Ventur. 2009, 24, 62-80. [CrossRef]

25. Segarra-Ciprés, M.; Bou-Llusar, J.C. External knowledge search for innovation: The role of firms' innovation strategy and industry context. J. Knowl. Manag. 2018, 22, 280-298. [CrossRef]

26. Xie, W.; White, S. From imitation to creation: The critical yet uncertain transition for Chinese firms. J. Technol. Manag. China 2006, 1, 229-242. [CrossRef]

27. Laursen, K.; Salter, A. Open for innovation: The role of openness in explaining innovation performance among UK manufacturing firms. Strateg. Manag. J. 2006, 27, 131-150. [CrossRef]

28. Hsu, J.Y.; Poon, J.P.; Yeung, H.W.C. External leveraging and technological upgrading among East Asian firms in the US. Eur. Plan. Stud. 2008, 16, 99-118. [CrossRef]

29. Li, H.; Zhang, Y.A.; Lyles, M. Knowledge spillovers, search, and creation in China's emerging market. Manag. Organ. Rev. 2013, 9, 395-412. [CrossRef]

30. Urban, F.; Zhou, Y.; Nordensvard, J.; Narain, A. Firm-level technology transfer and technology cooperation for wind energy between Europe, China and India: From North-South to South-North cooperation? Energy Sustain. Dev. 2015, 28, 29-40. [CrossRef]

31. Fu, X.; Pietrobelli, C.; Soete, L. The role of foreign technology and indigenous innovation in the emerging economies: Technological change and catching-up. World Dev. 2011, 39, 1204-1212. [CrossRef]

32. Wang, Y.; Ning, L.; Li, J.; Prevezer, M. Foreign Direct Investment Spillovers and the Geography of Innovation in Chinese Regions: The Role of Regional Industrial Specialization and Diversity. Reg. Stud. 2014, 50, 805-822. [CrossRef]

33. Liu, X.; Zou, H. The impact of greenfield FDI and mergers and acquisitions on innovation in Chinese high-tech industries. J. World Bus. 2008, 43, 352-364. [CrossRef]

34. Zhou, Y.; Pan, M.; Urban, F. Comparing the International Knowledge Flow of China's Wind and Solar Photovoltaic (PV) Industries: Patent Analysis and Implications for Sustainable Development. Sustainability 2018, 10, 1883. [CrossRef]

35. Nicholls-Nixon, C.L.; Woo, C.Y. Technology sourcing and output of established firms in a regime of encompassing technological change. Strateg. Manag. J. 2003, 24, 651-666. [CrossRef]

36. Arora, A.; Gambardella, A. Complementarity and external linkages: The strategies of the large firms in biotechnology. J. Ind. Econ. 1990, 38, 361-379. [CrossRef]

37. Fagerberg, J.; Verspagen, B. Technology-gaps, innovation-diffusion and transformation: An evolutionary interpretation. Res. Policy 2002, 31, 1291-1304. [CrossRef]

38. Katila, R.; Ahuja, G. Something old, something new: A longitudinal study of search behavior and new product introduction. Acad. Manag. J. 2002, 45, 1183-1194.

39. Hu, A.G.; Jaffe, A.B. Patent citations and international knowledge flow: the cases of Korea and Taiwan. Int. J. Ind. Organ. 2003, 21, 849-880. [CrossRef]

40. Narula, R.; Santangelo, G. Location, collocation and R\&D alliances in the European ICT industry. Res. Policy 2009, 38, 393-403.

41. Lee, K.; Lim, C.; Song, W. Emerging digital technology as a window of opportunity and technological leapfrogging: Catch-up in digital TV by the Korean firms. Int. J. Technol. Manag. 2005, 29, 40-63. [CrossRef]

42. Bell, M.; Pavitt, K. The development of technological capabilities. Trade Technol. Int. Compet. 1995, 22 , 69-101.

43. Krishnan, V.; Bhattacharya, S. Technology selection and commitment in new product development: The role of uncertainty and design flexibility. Manag. Sci. 2002, 48, 313-327. [CrossRef]

44. Kogut, B.; Zander, U. Knowledge of the Firm, Combinative Capabilities, and the Replication of Technology. Organ. Sci. 1992, 3, 383-397. [CrossRef]

45. Duysters, G.; Lokshin, B. Determinants of alliance portfolio complexity and its effect on innovation performance of companies. J. Prod. Innovat. Manag. 2011, 28, 570-585. [CrossRef] 
46. Lin, J.Y. Effects on diversity of R\&D sources and human capital on industrial performance. Technol. Forecast. Soc. 2014, 85, 168-184.

47. Doranova, A.; Costa, I.; Duysters, G. Knowledge base determinants of technology sourcing in clean development mechanism projects. Energ. Policy 2010, 38, 5550-5559. [CrossRef]

48. Findlay, R. Relative backwardness, direct foreign investment, and the transfer of technology: A simple dynamic model. Quart. J. Econ. 1978, 92, 1-16. [CrossRef]

49. Wang, J.Y.; Blomström, M. Foreign investment and technology transfer: A simple model. Eur. Econ. Rev. 1992, 36, 137-155. [CrossRef]

50. Haddad, M.; Harrison, A. Are there positive spillovers from direct foreign investment? Evidence from panel data for Morocco. J. Dev. Econ. 1993, 42, 51-74. [CrossRef]

51. Li, W.; Guo, B.; Xu, G. Making the next move: When does the newness of experience matter in overseas sequential entries of multinational companies? Int. Bus. Rev. 2017, 26, 908-926. [CrossRef]

52. Candi, M.; Van den Ende, J.; Gemser, G. Organizing innovation projects under technological turbulence. Technovation 2013, 33, 133-141. [CrossRef]

53. Eisenhardt, K.M.; Tabrizi, B.N. Accelerating adaptive processes. Product Innovation in the global computer industry. Admin. Sci. Quart. 1995, 40, 84-110. [CrossRef]

54. Kim, L. Imitation to Innovation: The Dynamics of Korea's Technological Learning; Harvard Business School Press: Boston, MA, USA, 1997.

55. Ahuja, G.; Katila, R. Technological acquisitions and the innovation performance of acquiring firms: A longitudinal study. Strateg. Manag. J. 2001, 22, 197-220. [CrossRef]

56. Guo, B.; Pang, X.; Li, W. The role of top management team diversity in shaping the performance of business model innovation: A threshold effect. Technol. Anal. Strateg. 2018, 30, 241-253. [CrossRef]

57. Leiponen, A.; Helfat, C.E. Innovation objectives, knowledge sources, and the benefits of breadth. Strateg. Manag. J. 2010, 31, 224-236. [CrossRef]

58. Liu, X.; White, R.S. The relative contributions of foreign technology and domestic inputs to innovation Chinese manufacturing industries. Technovation 1997, 17, 119-125. [CrossRef]

59. Buckley, P.J.; Wang, C.; Clegg, J. The Impact of Foreign Ownership, Local Ownership and Industry Characteristics on Spillover Benefits from Foreign Direct Investment in China. Int. Bus. Rev. 2007, 16, 142-158. [CrossRef]

60. Fujimori, A.; Sato, T. Productivity and technology diffusion in India: The spillover effects from foreign direct investment. J. Policy Model. 2015, 37, 630-651. [CrossRef]

61. Blomström, M.; Persson, H. Foreign investment and spillover efficiency in an underdeveloped economy: Evidence from the Mexican manufacturing industry. World Dev. 1983, 11, 493-501. [CrossRef]

62. Liu, W.; Wei, Q.; Huang, S.-Q.; Tsai, S.-B. Doing Good Again? A Multilevel Institutional Perspective on Corporate Environmental Responsibility and Philanthropic Strategy. Int. J. Environ. Res. Public Health 2017, 14, 1283. [CrossRef] [PubMed]

63. Guo, B.; Chen, X. Why are the industrial firms of emerging economies short-termistic in innovation? Industry-level evidence from Chinese manufacturing. Int. J. Technol. Manag. 2012, 59, 273-299. [CrossRef]

64. Ferreras-Méndez, J.L.; Newell, S.; Fernández-Mesa, A.; Alegre, J. Depth and breadth of external knowledge search and performance: The mediating role of absorptive capacity. Ind. Market. Manag. 2015, 47, 86-97. [CrossRef]

65. del-Corte-Lora, V.; Molina-Morales, F.X.; Vallet-Bellmunt, T.M. Mediating effect of creativity between breadth of knowledge and innovation. Technol. Anal. Strateg. Manag. 2016, 28,768-782. [CrossRef]

66. Kim, C.Y.; Lim, M.S.; Yoo, J.W. Ambidexterity in External Knowledge Search Strategies and Innovation Performance: Mediating Role of Balanced Innovation and Moderating Role of Absorptive Capacity. Sustainability 2019, 11, 5111. [CrossRef]

(C) 2020 by the authors. Licensee MDPI, Basel, Switzerland. This article is an open access article distributed under the terms and conditions of the Creative Commons Attribution (CC BY) license (http://creativecommons.org/licenses/by/4.0/). 